\title{
PENGARUH RASIO KEUANGAN TERHADAP PROFITABILITAS PERBANKAN SYARIAH INDONESIA
}

\author{
Nur Janah \\ janahn531@yahoo.com \\ Sekolah Tinggi Agama Islam Panca Budi Perdagangan Simalungun \\ Pani Akhiruddin Siregar \\ siregarpaniakhiruddin@yahoo.co.id \\ Sekolah Tinggi Agama Islam Panca Budi Perdagangan Simalungun
}

\begin{abstract}
This study aims to analyze the influence of CAR, NPF, FDR and BOPO on the profitability of Indonesian Sharia Banking. Research approach with quantitative methods using secondary data. Quantitative data types consist of monthly time series data from SPS BI atau OJK on year 2006 until 2017. The research model is described in multiple linear regression analysis equations. With a significance level of 0.05 . From the F test results, CAR, NPF, FDR and BOPO variables simultaneously significantly affect to ROA. This shows the regression model on CAR, NPF, FDR and BOPO can be used to predict ROA. There is significantly between independent variables to ROA variables. From t test results, CAR variables have no effect and not significant to ROA variables, NPF and BOPO variables have no effect and significant to ROA variable. While FDR variables have an effect and significant to ROA variable. The model estimation obtained $\mathrm{R}$ value of 0.860 and R Square determination coefficient of 0.740 which means $74 \%$ of the variation of the dependent variable can be explained by the independent variables in the model. While the reduce $26 \%$ is explained by other causes that are not included in the model.
\end{abstract}

Keywords: Financial Ratio, CAR, ROA, NPF, FDR, BOPO, Provitability, Islamic Banking

\begin{abstract}
Abstrak
Penelitian ini bertujuan untuk menganalisis seberapa besar pengaruh CAR, NPF, FDR dan BOPO terhadap profitabilitas Perbankan Syariah Indonesia.Pendekatan penelitian dengan metode kuantitatif menggunakan data sekunder. Jenis data kuantitatif berupa data runtun waktu (time series) bulanan dari SPS BI atau OJK dari tahun 2006 sampai 2017. Model penelitian dijabarkan dalam persamaan analisis regresi linier berganda. Dengan taraf signifikansi 0,05. Dari hasil uji F, variabel CAR, NPF, FDR dan BOPO secara simultan signifikan mempengaruhi variabel ROA. Hal ini menunjukkan model regresi pada CAR, NPF, FDR dan BOPO bisa dipakai untuk memprediksi ROA. Hipotesisnya terdapat pengaruh yang signifikan antara variabel bebas terhadap variabel ROA.Dari hasil uji t,
\end{abstract}


variabel CAR tidak berpengaruh dan tidak signifikan terhadap variabel ROA, variabel NPF dan BOPO tidak berpengaruh dan signifikan terhadap variabel ROA.Sedangkan variabel FDR berpengaruh dan signifikan terhadap variabel ROA. Dari hasil estimasi model, diperoleh nilai $\mathrm{R}$ sebesar 0,860 dan koefisien determinasi R Square sebesar sebesar 0,740 yang berarti $74 \%$ dari variasi variabel terikat bisa dijelaskan oleh variabel bebas dalam model tersebut. Sedangkan sisanya, yaitu $26 \%$ dijelaskan oleh sebab-sebab yang lain yang tidak masuk dalam model.

Kata kunci: Rasio keuangan, CAR, ROA, NPF, FDR, BOPO, profitabilitas, perbankan syariah

\section{Pendahuluan}

Dalam Undang-Undang Nomor 21 tahun 2008 tentang Perbankan Syariah menyatakan bahwa bank syariah adalah bank yang menjalankan kegiatan usahanya berdasarkan prinsip syariah dan menurut jenisnya terdiri atas bank umum syariah dan bank pembiayaan rakyat syariah. Sedangkan yang dimaksud dengan perbankan syariah adalah segala sesuatu yang menyangkut tentang bank syariah dan unit usaha syariah, mencakup kelembagaan, kegiatan usaha serta cara dan proses dalam melaksanakan kegiatan usahanya. Pengertian bank syariah ${ }^{1}$ sering disamakan dengan pengertian perbankan syariah. Padahal dua hal ini amat berbeda. Perbankan syariah ini lebih komprehensif dibandingkan dengan bank syariah karena bank syariah hanya aspek kelembagaan.

Perbankan di Indonesia semakin ramai dengan adanya bank syariah ${ }^{2}$ yang menawarkan produk keuangan dan investasi dengan cara yang berbeda dibanding dengan bank konvensional yang sudah lama ada. Walaupun dianggap pendatang baru, perkembangan perbankan syariah cukuplah pesat. Sebagai negara dengan penduduk muslim terbesar, sudah sepatutnya Indonesia menjadi pelopor dan kiblat pengembangan keuangan syariah di dunia, khususnya perbankan syariah. Bahkan bank konvensional di Indonesia ikutan ambil bagian untuk mendirikan bank syariah atau unit usaha syariah. Hal ini dilakukan untuk mendapatkan lebih banyak nasabah yang tertarik dengan keunggulan bank syariah karena berdasarkan hukum Islam ${ }^{3}$, perbankan syariah tidak mengenal bunga pinjaman dikarenakan bunga pinjaman dianggap riba dan berdosa. ${ }^{4}$ 
Untuk menjaga agar aktivitas perbankan tetap eksis dan terus memberikan keuntungan, setiap manajemen bank diminta untuk menjaga kesehatan bank dari waktu ke waktu yang berarti bank harus dinilai kesehatannya setiap periode. Penilaian kesehatan bank juga dilakukan untuk bank syariah baik bank umum syariah maupun bank pembiayaan rakyat syariah. Hal ini dilakukan sesuai dengan perkembangan metodologi penilaian kondisi bank yang bersifat dinamis yang mendorong pengaturan kembali sistem penilaian tingkat kesehatan bank ${ }^{5}$ berdasarkan prinsip syariah. Dalam penilaian tingkat kesehatan bank, bank syariah telah memasukkan risiko yang melekat pada aktivitas bank (inherent risk) yang merupakan bagian dari proses penilaian manajemen risiko. ${ }^{6}$ Oleh karena itu, dalam penentuan tingkat kesehatan sebuah bank, Bank Indonesia lebih mementingkan penilaian Return on Assets (ROA) daripada Return on Equity (ROE) karena Bank Indonesia lebih mengutamakan nilai profitabilitas suatu bank yang diukur dengan aset yang dananya sebagian berasal dari dana simpanan masyarakat, sehingga ROA lebih mewakili dalam mengukur tingkat profitabilitas perbankan. $^{7}$

\section{Perbankan Syariah}

Bank dalam kegiatan operasionalnya sebagai sebuah lembaga keuangan yang berfungsi sebagai intermediasi antara pihak surplus dana dengan pihak defisit dana selalu penuh dengan risiko. Bank menarik dana dari masyarakat (surplus dana) dengan menawarkan berbagai jenis produk simpanan seperti giro, tabungan dan deposito yang hampir kesemuanya berjangka pendek (kurang dari setahun). Sementara di sisi lain, bank menyalurkan dana kepada masyarakat (defisit dana) dalam bentuk pinjaman maupun pembiayaan yang hampir kesemuanya berjangka panjang (lebih dari setahun) dan tidak dapat dilikuidasi dalam waktu singkat. Ketidakcocokan waktu inilah yang menjadi sumber utama risiko pada perbankan. Bank sebesar dan semapan apa pun akan jatuh dalam waktu singkat sekiranya semua nasabah (pihak surplus dana) dalam waktu yang bersamaan menarik dananya (bank rush) sementara berbagai pinjaman atau pembiayaan yang disalurkan ke nasabah (pihak defisit dana) tidak dapat segera dicairkan. Oleh karena itu, risiko yang melekat pada lembaga keuangan tidak dapat dihilangkan dan tentunya akan selalu membayangi kegiatan operasional 


\section{Pengaruh Rasio Keuangan Terhadap Profitabilitas Perbankan Syariah 624 Indonesia (Nur Janah dan Pani Akhiruddin Siregar )}

bank setiap saat ${ }^{8}$ terlebih perbankan syariah. Penurunan kinerja perbankan syariah dapat menurunkan pula kepercayaan masyarakat.

Sistem perbankan syariah yang ingin diwujudkan oleh Bank Indonesia adalah perbankan syariah yang modern yang bersifat universal dan terbuka bagi seluruh masyarakat Indonesia tanpa terkecuali. Sebuah sistem perbankan yang menghadirkan bentuk-bentuk aplikatif dari konsep ekonomi syariah yang dirumuskan secara bijaksana, dalam konteks kekinian permasalahan yang sedang dihadapi oleh bangsa Indonesia dan dengan tetap memperhatikan kondisi sosiokultural di mana bangsa ini menuliskan perjalanan sejarahnya. Hanya dengan cara demikian, upaya pengembangan sistem perbankan syariah senantiasa dilihat dan diterima oleh segenap masyarakat Indonesia sebagai bagian dari solusi atas berbagai permasalahan negeri sesuai cetak biru pengembangan perbankan syariah di Indonesia yang memuat visi, misi dan sasaran pengembangan perbankan syariah yang diarahkan untuk memberikan kemaslahatan terbesar bagi masyarakat dan berkontribusi secara optimal bagi perekonomian nasional. ${ }^{9}$

\section{Analisis Rasio Keuangan}

Rasio keuangan adalah suatu kajian yang melihat perbandingan antara jumlah-jumlah yang terdapat pada laporan keuangan dengan mempergunakan formula-formula yang dianggap representatif. Rasio keuangan (financial ratio) sangat penting gunanya untuk melakukan analisa terhadap kondisi keuangan dengan membandingkan rasio pada saat sekarang dengan rasio pada saat yang akan datang. Dipergunakannya analisis rasio keuangan memberikan gambaran tentang keadaan perusahaan dan dapat dijadikan sebagai alat prediksi bagi perusahaan tersebut di masa yang akan datang. ${ }^{10}$

\section{Capital Adequacy Ratio (CAR)}

Rasio kecukupan modal bank disebut CAR dimaksudkan untuk menutupi potensi kerugian yang tidak terduga (unexpected loos) dan sebagai cadangan pada saat terjadi krisis perbankan. ${ }^{11}$ Rasio CAR memperlihatkan seberapa jauh seluruh aktiva bank yang mengandung risiko (kredit, penyertaan, surat berharga, tagihan 
pada bank lain) ikut dibiayai dari dana modal sendiri bank di samping memperoleh dana-dana dari sumber di luar bank, seperti dana masyarakat, pinjaman (utang) dan lain-lain. Rasio CAR ini juga digunakan untuk memenuhi keamanan dan kesehatan bank dari sisi modal pemiliknya. Jika semakin tinggi CAR, maka semakin baik kinerja bank tersebut. ${ }^{12}$ Oleh Bank Indonesia, CAR disyaratkan minimal $8 \%$.

\section{Retun on Assets (ROA)}

ROA adalah rasio yang menggambarkan kemampuan bank dalam mengelola dana yang diinvestasikan dalam keseluruhan aset yang menghasilkan keuntungan. ${ }^{13}$ Rasio profitabilitas ini sekaligus menggambarkanefisiensi kinerja bank yang bersangkutan dikarenakan rasio ini mengutamakan nilai profitabilitas suatu bank yangdiukur dengan aset produktif yang dananya sebagian besar berasal dari danapihak ketiga (DPK). Jika semakin besar ROA suatu bank, makasemakin besar pula tingkat keuntungan yang dicapai bank tersebut dansemakin baik pula posisi bank tersebut dari segi penggunaan aset. Oleh Bank Indonesia, ROA disyaratkan minimal $0,5 \%$.

\section{Non Performing Financing(NPF)}

Dalam menjalankan bisnis perbankan yang penuh dengan risiko, bank syariah juga tidak terlepas dari risiko pembiayaan bermasalah (Non Performing Financing/NPF), sehingga bank syariah perlu mengatur strategi agar tingkat NPF di bank syariah tidak dalam kondisi yang mengkhawatirkan. ${ }^{14}$ Risiko pembiayaan ini dapat terjadi akibat kegagalan atau ketidakmampuan nasabah dalam pengembalian jumlah pinjaman yang diterima dari bank syariah beserta bagi hasilnya sesuai dengan jangka waktu yang telah dijadwalkan. ${ }^{15}$ Kualitas pembiayaan kurang lancar, diragukan dan macet. Jika semakin besar NPF, maka semakin buruk kinerja bank syariah tersebut. Oleh Bank Indonesia, NPF disyaratkan minimal $5 \%$.

\section{Biaya Operasional Terhadap Pendapatan Operasional (BOPO)}

Biaya Operasional Terhadap Pendapatan Operasional disebut BOPO adalah rasio yang digunakan untuk mengukur tingkat efisiensi dan kemampuan 
bank dalam melakukan kegiatan operasionalnya ${ }^{16}$ atau BOPO merupakan rasio biaya operasional dalam 12 bulan terakhir terhadap pendapatan operasional dalam periode yang sama.Jika semakin kecil BOPO, maka semakin efisien biaya operasional yang dikeluarkan bank yang bersangkutan. Oleh Bank Indonesia, BOPO disyaratkan minimal $85 \% .^{17}$

\section{Financing to Deposit Ratio (FDR)}

Pada umumnya, konsep yang sama ditunjukkan padabank syariah dalam mengukur likuiditas,yakni dengan menggunakanFinancing to Deposit Ratio (FDR) yang menyatakan seberapa besar DPK bank syariah dilepaskan untuk pembiayaan. ${ }^{18}$ Peningkatan DPK tanpa diimbangi peningkatan pembiayaan akan mengurangi bagi hasil yang diterima nasabah. Jika semakin rendah FDR, maka menunjukkan kurangnya efektifitas bank syariah dalam menyalurkan pembiayaan. Oleh Bank Indonesia, FDR disyaratkan minimal 85\%.

\section{Return On Equity (ROE)}

ROE adalah rasio yang digunakan untuk mengkaji sejauh mana suatu perusahaan mempergunakan sumber daya yang dimiliki untuk mampu memberikan laba ekuitas. ${ }^{19}$ Dengan demikian, ROE ini menghubungkan laba bersih yang diperoleh dari operasi perusahaan dengan jumlah modal sendiri yang dimiliki. Jika semakin tinggi ROE, maka suatu perusahaan memiliki suatu peluang untuk memberikan pendapatan yang besar bagi pemegang saham. Dalam hal ini akan berdampak pada peningkatan harga saham. Oleh Bank Indonesia, ROE disyaratkan minimal 5\%.

\section{Profitabilitas}

Profitabilitas disebut juga rentabilitas rasio digunakan untuk mengukur tingkat efisiensi usaha dan profitabilitas yang dicapai bank yang bersangkutan ${ }^{20}$ atau profitabilitas bank adalah rasio yang digunakan untuk mengukur kemampuan bank dalam menghasilkan laba dari aktivitas normal bisnisnya. ${ }^{21}$ 


\section{Metode Penelitian}

Metode penelitian pada dasarnya merupakan cara ilmiah untuk mendapatkan data dengan tujuan dan kegunaan tertentu. Cara ilmiah mempunyai karakteristik rasional, empiris dan sistematis. ${ }^{22}$ Pendekatan penelitian dengan pendekatan kuantitatif disebut metode kuantitatif (scientific paradigm/paradigma ilmiah). Model penelitian dijabarkan dalam persamaan analisis regresi berganda dengan model linier dengan persamaan:

$$
Y=a+b_{1} X_{1}+b_{2} X_{2}+b_{3} X_{3}+b_{4} X_{4}+e
$$

Keterangan:

\begin{tabular}{|c|l|c|l|}
\hline $\mathrm{Y}$ & ROA & $\mathrm{X}_{2}$ & $\mathrm{NPF}$ \\
$\mathrm{a}$ & Konstanta (intercept) & $\mathrm{X}_{3}$ & FDR \\
$\mathrm{b}_{1}, \mathrm{~b}_{2}, \mathrm{~b}_{3}$ & Koefisien regresi & $\mathrm{X}_{4}$ & BOPO \\
$\mathrm{X}_{1}$ & CAR & $\mathrm{E}$ & Standar eror \\
\hline
\end{tabular}

\section{Hasil Penelitian}

Hasil penelitian merupakan bagian yang terpenting yang menyajikan hasilhasil analisis data yang dilaporkan. Proses analisis data (seperti hitungan statistik) perlu disajikan. Proses pengujian hipotesis termasuk perbandingan antara koefisien yang ditemukan dalam analisis dengan koefisien dalam tabel statistik, dituliskan di sini.

\section{Uji Normalitas}

Uji normalitas merupakan salah satu bagian dari uji persyaratan analisis data.Artinya, sebelum kita melakukan analisis data yang sesungguhnya, data penelitian tersebut harus diuji kenormalan distribusinya. ${ }^{23}$ 


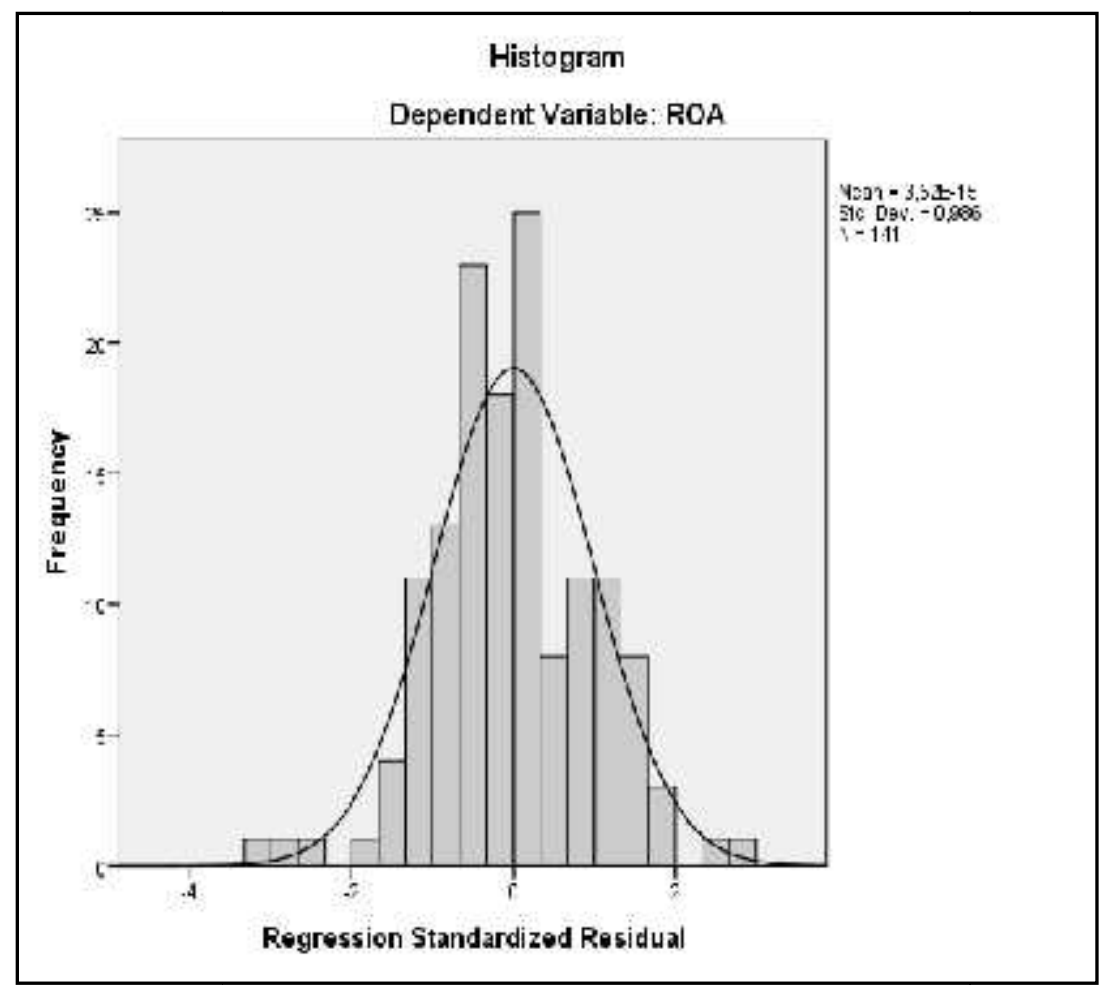

Sumber: Data primer yang diolah

Gambar 1 Grafik Histogram Display Normal Curve

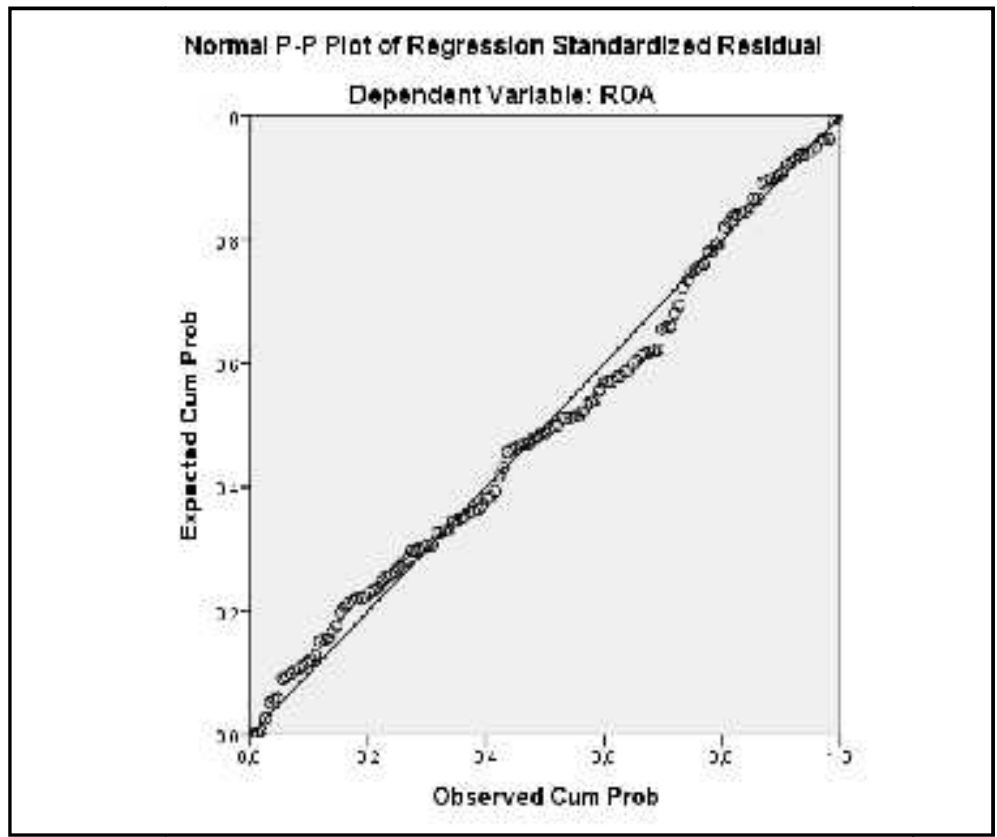

Sumber: Data primer yang diolah

\section{Gambar 2 Grafik Normal Probability Plot}

Dari Gambar 1 data distribusi nilai residual (error) menunjukkan distribusi normal (lihat gambar berbentuk bel). Gambar 2 terlihat titik-titik menyebar di 
sekitar garis diagonal serta arah penyebarannya mengikuti arah garis diagonal dan sebaran eror (berupa titik) masih ada disekitaran garis lurus. Kedua hal ini menunjukkan model regresi memenuhi asumsi normalitas atau residual dari model dapat dianggap berdistribusi normal. ${ }^{24}$

Tabel 1 Hasil Uji Kolmogorov Smirnov (K-S)

One-Sample Kolmogorov-Smirnov Test

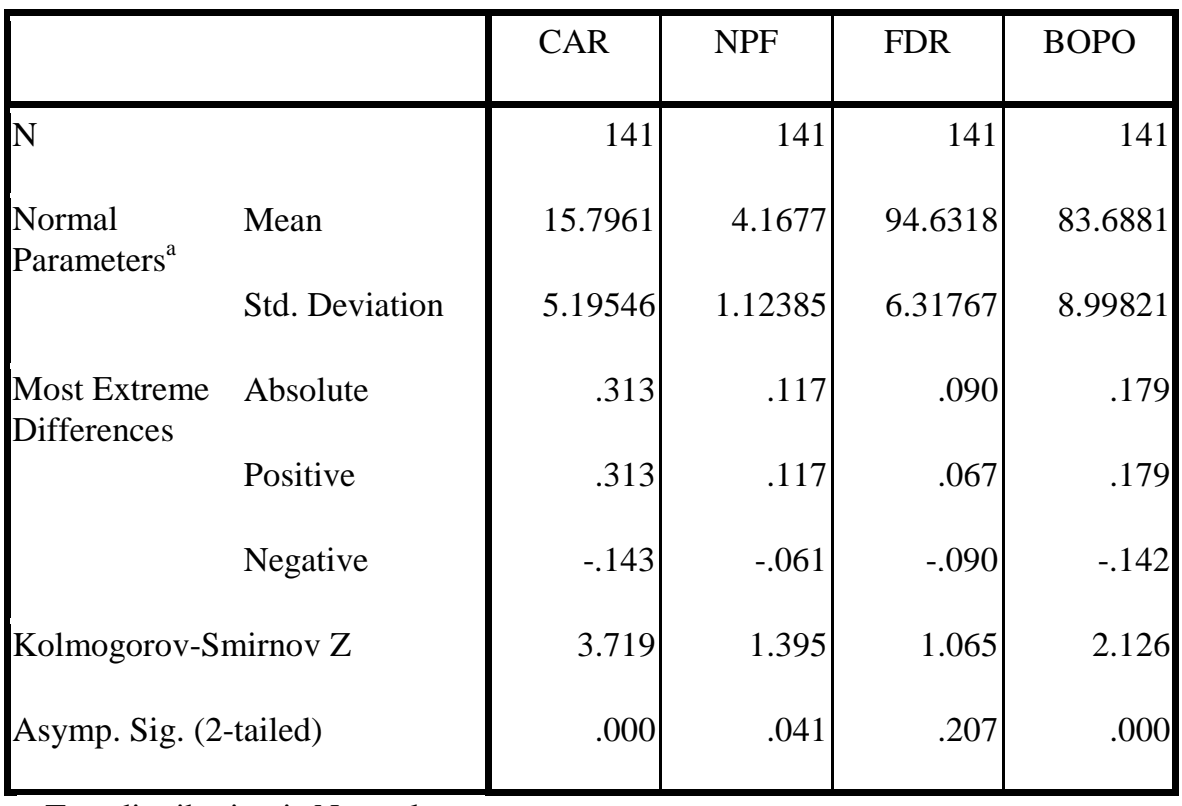

a. Test distribution is Normal.

Sumber: Data primer yang diolah

Dari tabel di atas, dapat dianalisis dan diambil kesimpulan:

1. Dari hasil Absolute hitung, variabel CAR probabilitas 0,313, variabel NPF probabilitas 0,117, variabel FDR probabilitas 0,090 dan variabel BOPO probabilitas 0,179 . Nilai K-S tabel probabilitas 0,1137 $(\mathrm{n}=141)$. Dengan demikian, variabel FDR saja yang berdistribusi normal dikarenakan nilai K$\mathrm{S}_{\text {hitung }}(0,90)$ lebih kecil dari nilai $\mathrm{K}-\mathrm{S}_{\text {tabel }}(0,1137)$.

2. Dengan melihat "Asymp. Sig (2-tailed)" baris paling bawah, variabel FDR yang memiliki signifikansi di atas 0,05 (probabilitas 0,207). Hipotesis nol diterima yang artinya variabel terdistribusi dengan normal. Sama halnya dari

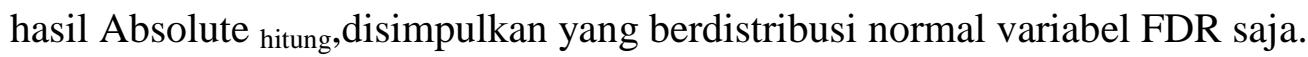




\section{Uji Multikolinieritas}

Uji multikolinieritas digunakan untuk mengetahui ada atau tidaknya penyimpangan asumsi klasik multikolinieritas, yakni adanya hubungan linier antar variabel independen dalam model regresi. Persyaratan yang harus terpenuhi dalam model regresi adalah tidak adanya multikolinieritas.

Tabel 2 Hasil Uji Multikolinieritas

Sumber: Data primer yang diolah

\begin{tabular}{|l|r|r|}
\hline Model & \multicolumn{2}{|c|}{ Collinearity Statistics } \\
\cline { 2 - 3 } & Tolerance & \multicolumn{1}{|c|}{ VIF } \\
\hline CAR & .978 & 1.023 \\
NPF & .958 & 1.044 \\
FDR & .604 & 1.655 \\
BOPO & .580 & 1.724 \\
\hline
\end{tabular}

Dari tabel di atas dapat dianalisis dan diambil kesimpulan bahwa tidak terdapat gejala multikolinieritas pada keseluruhan variabel independen dikarenakan nilai VIF di sekitar angka 1 atau lebih kecil dari 10 yang menyimpulkan bahwa uji multikolinieritas terpenuhi.

\section{Uji Heteroskedastisitas}

Uji heteroskedastisitas digunakan untuk mengetahui ada atau tidaknya penyimpangan asumsi klasik heteroskedastisitas, yakni adanya ketidaksamaan varian dari residual (kesalahan pengganggu) untuk semua pengamatan pada model regresi. Persyaratan yang harus terpenuhi dalam model regresi adalah tidak adanya gejala heteroskedastisitas. ${ }^{25}$

\section{Gambar 3 Grafik Scatterplot}




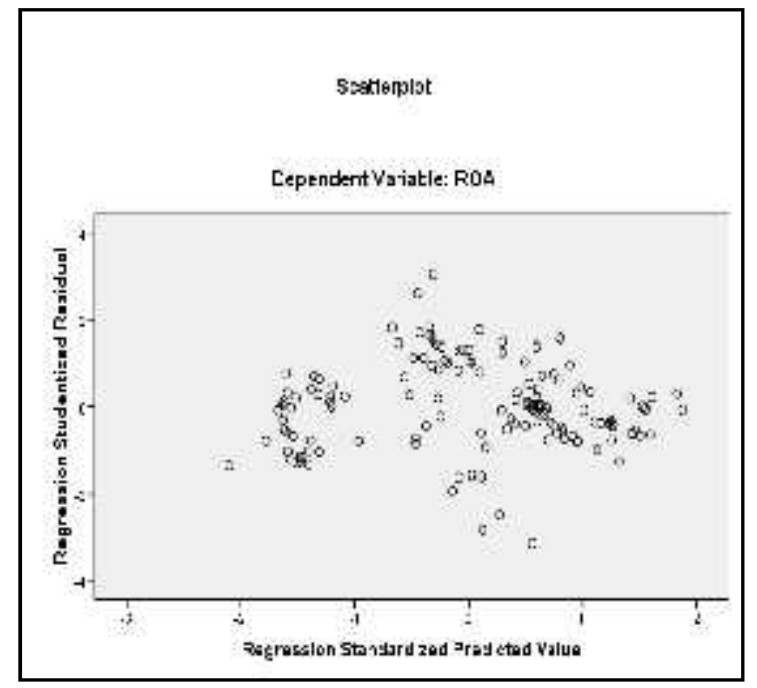

Sumber: Data primer yang diolah

Dari Gambar 3 tampak titik-titik tidak membentuk pola yang jelas dan titik-titik menyebar di atas dan di bawah angka 0 pada sumbu Y. Hal ini menunjukkan model regresi bebas dari heteroskedastisitas.

\section{Tabel 3 Hasil Uji Glejser}

\begin{tabular}{|l|c|}
\hline \multicolumn{1}{|c|}{ Model } & Sig. \\
& .000 \\
\hline (Constant) & .063 \\
CAR & .000 \\
NPF & .000 \\
FDR & .000 \\
BOPO & \\
\hline
\end{tabular}

Sumber: Data primer yang diolah

Pada uji Glejser yang ditunjukkan dalam Tabel 3 terjadi masalah heteroskedastisitas dikarenakan nilai signifikansi variabel NPF, variabel FDR dan variabel BOPO lebih kecil dari 0,05 (probabilitas kesemuanya sama 0,000). Namun, tidak terjadi heteroskedastisitas pada variabel CAR dikarenakan nilai signifikansinya lebih besar dari 0,05 (probabilitas 0,063) yang menunjukkan model regresi variabel CAR bebas dari gangguan heteroskedastisitas. 


\section{Uji Autokorelasi}

Ujiautokorelasi digunakan untuk mengetahui ada atau tidaknya penyimpangan asumsi klasik autokorelasi, yakni korelasi yang terjadi antara residual pada satu pengamatan dengan pengamatan lain pada model regresi. Model regresi yang baik adalah regresi yang bebas dari autokorelasi. Metode pengujian yang sering digunakan dengan uji Durbin-Watson (uji DW).

Tabel 4 Hasil Uji Autokorelasi

Model Summary ${ }^{b}$

\begin{tabular}{|l|r|r|r|r|r|}
\hline Model & \multicolumn{1}{|c|}{$\mathrm{R}$} & R Square & $\begin{array}{c}\text { Adjusted R } \\
\text { Square }\end{array}$ & $\begin{array}{c}\text { Std. Error of } \\
\text { the Estimate }\end{array}$ & \multicolumn{1}{c|}{$\begin{array}{c}\text { Durbin- } \\
\text { Watson }\end{array}$} \\
\hline 1 & $.860^{\mathrm{a}}$ & .740 & .733 & .28941 & .665 \\
\hline
\end{tabular}

a. Predictors: (Constant), BOPO, CAR, NPF, FDR

b. Dependent Variable: ROA

Sumber: Data primer yang diolah

Dari Tabel 4 nilai DW hitung adalah sebesar 0,665 di mana nilai tersebut kurang dari nilai DL pada $\mathrm{K}=4$ dan $\mathrm{t}=141$, sehingga terdapat masalah autokorelasi positif (DW<DL). Dengan tabel signifikansi 0,05, nilai Durbin Lower (DL) pada $\mathrm{K}=4$ dan $\mathrm{t}=141$ berdasarkan tabel Durbin Watson adalah sebesar 1,6670. Sedangkan nilai Durbin Upper (DU) sebesar 1,7835. Kesimpulannya hipotesis nol ditolak yang berarti terdapat autokorelasi. ${ }^{26}$

Tabel 5 Hasil Uji Runs (Runs Test)

\section{Runs Test}

\begin{tabular}{|l|r|}
\hline & $\begin{array}{r}\text { Unstandardiz } \\
\text { ed Residual }\end{array}$ \\
\hline Test Value &, 84837 \\
Cases < Test Value & 140 \\
\hline
\end{tabular}




$\mid$\begin{tabular}{l|r} 
Cases $>=$ Test & 1 \\
Value & 141 \\
Total Cases & 3 \\
Number of Runs &, 120 \\
$Z$ &, 905 \\
$\begin{array}{l}\text { Asymp. Sig. (2- } \\
\text { tailed) }\end{array}$
\end{tabular}

Sumber: Data primer yang diolah

Dari Tabel 5 menunjukkan bahwa nilai Asymp. Sig. (2-tailed) lebih besar dari 0,05 (probabilitas 0,905) yang berarti hipotesis nol gagal ditolak. Dengan demikian, data yang dipergunakan cukup acak, sehingga tidak terdapat masalah autokorelasi pada data yang diuji.

\section{Uji Koefisien Determinasi $\left(\mathbf{R}^{2}\right)$}

Koefisien determinasi R Square $\left(\mathrm{R}^{2}\right)$ digunakan untuk mengukur proporsi variasi variabel terikat yang dijelaskan oleh variabel bebas.

\section{Tabel 6 Hasil Uji R Square}

Model Summary ${ }^{b}$

\begin{tabular}{|l|r|r|r|r|}
\hline Model & \multicolumn{1}{|c|}{$\mathrm{R}$} & R Square & $\begin{array}{c}\text { Adjusted R } \\
\text { Square }\end{array}$ & $\begin{array}{l}\text { Std. Error of } \\
\text { the Estimate }\end{array}$ \\
\hline 1 & $.860^{\mathrm{a}}$ & .740 & .733 & .28941 \\
\hline
\end{tabular}

a. Predictors: (Constant), BOPO, CAR, NPF, FDR

b. Dependent Variable: ROA

Sumber: Data primer yang diolah menggunakaan SPSS.

Dari hasil estimasi model di atas diperoleh nilai $\mathrm{R}$ sebesar 0,860 sebagai nilai korelasi berganda yang artinya CAR, NPF, FDR dan BOPO memiliki keeratan hubungan yang tinggi dengan ROA. Nilai R Square dan Adjusted R Square mewakili nilai koefisien determinasi. Penulis menggunakan nilai R Square sebagai koefisien determinasi sebesar 0,740 yang berarti $74 \%$ dari variasi variabel 
ROA bisa dijelaskan oleh variabel independen (CAR, NPF, FDR dan BOPO) dalam model tersebut. Sedangkan sisanya $(100 \%-74 \%=26 \%)$ dijelaskan oleh sebab-sebab yang lain yang tidak masuk dalam model.

\section{Uji F (Uji Simultan)}

Uji F disebut juga uji Analysis of Varian (ANOVA) digunakan untuk melihat pengaruh variabel bebas terhadap variabel terikat secara serempak.

\section{Tabel 7 Hasil Uji F (Uji ANOVA)}

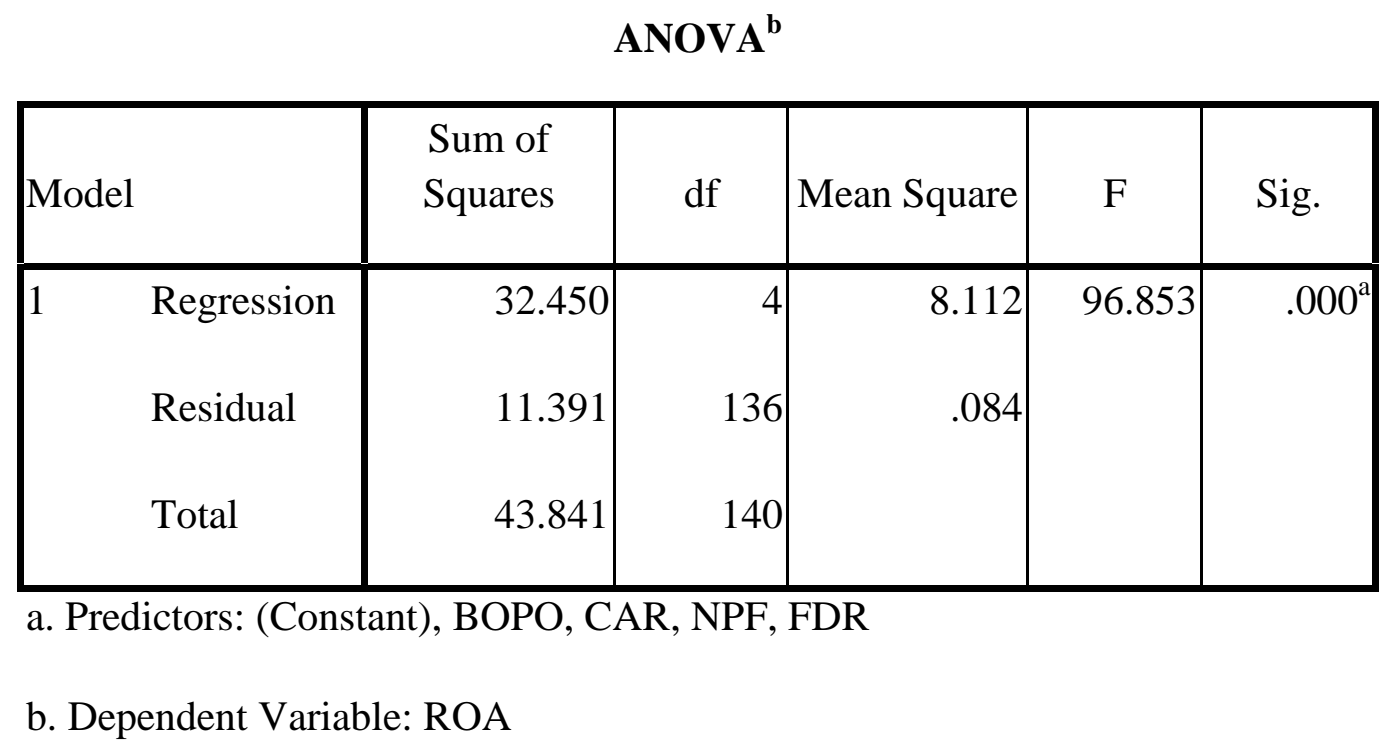

Sumber: Data primer yang diolah

Dari Tabel 5 hasil uji F atau uji ANOVA, analisis dan kesimpulannya adalah:

1. Didapat nilai $F$ hitung sebesar 96,853. Dari tabel distribusi $F$ dengan taraf signifikansi 0,05, nilai $\mathrm{F}_{\text {tabel }}$ sebesar 2,43 (n-k-1), sehingga $\mathrm{H}_{0}$ ditolak dan $\mathrm{H}_{\mathrm{a}}$ diterima $(96,853>2,43)$. Kesimpulannya variabel CAR, variabel NPF, variabel FDR dan variabel BOPO (secara simultan) signifikan mempengaruhi variabel ROA.

2. Didapat nilai signifikansi 0,000 lebih kecil dari 0,05 . Hal ini menunjukkan model regresi pada variabel CAR, variabel NPF, variabel FDR dan variabel BOPO bisa dipakai untuk memprediksi variabel ROA. 


\section{Uji t (Uji Parsial)}

Uji t digunakan untuk melihat pengaruh variabel-variabel bebas secara parsial terhadap variabel terikatnya.

Tabel 8 Hasil Uji t (Uji Parsial)

Coefficients $^{\mathbf{a}}$

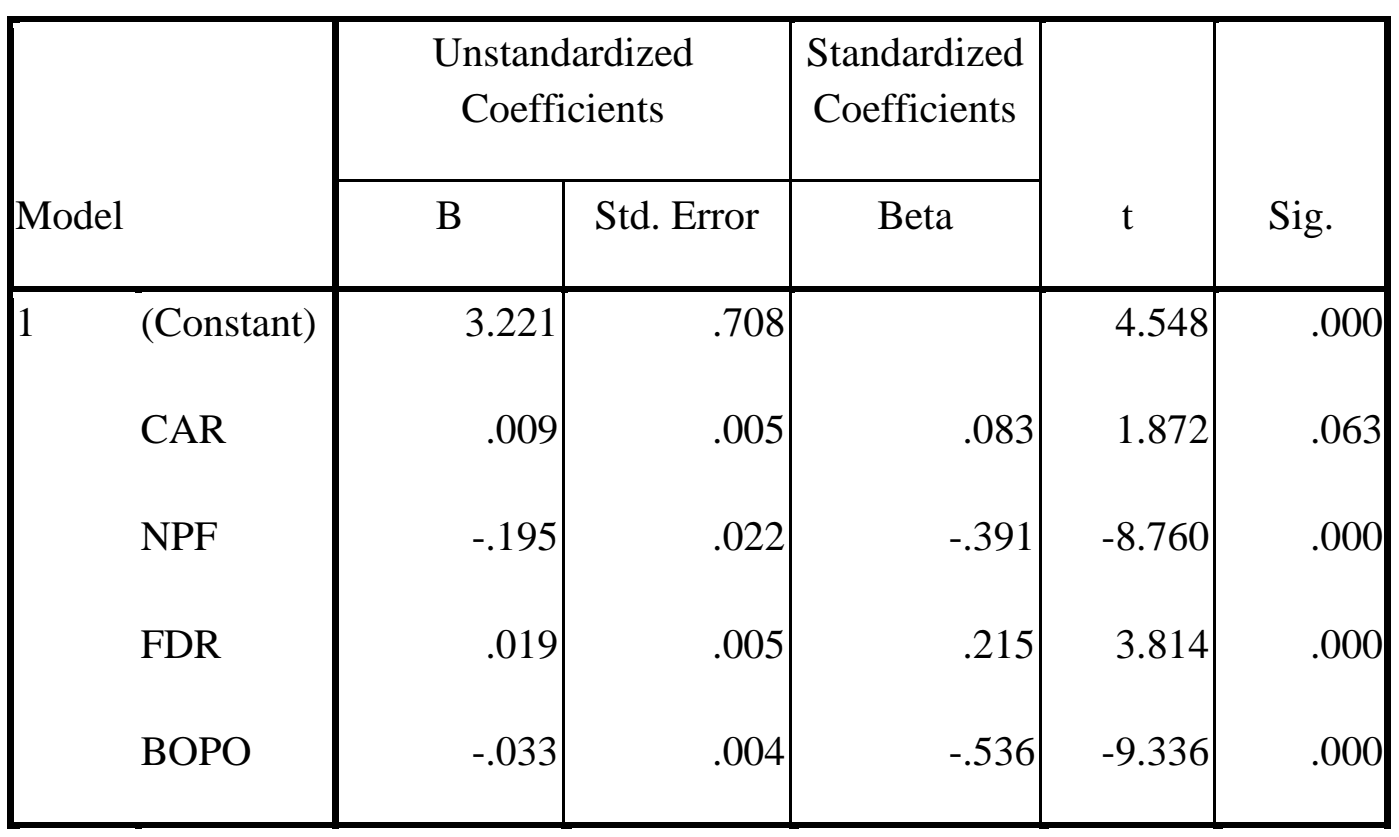

a. Dependent Variable: ROA

Sumber: Data primer yang diolah

Uji t untuk menguji signifikansi konstanta dan variabel dependen (ROA). Analisis dan kesimpulan sebagai berikut:

1. Dengan taraf signifikansi $0,05, \mathrm{n}=141$ (jumlah sampel), $\mathrm{k}=4$ (jumlah variabel independen), diperoleh $\mathrm{t}_{\text {tabel }}=1,960$ :

a. $\quad t_{\text {hitung }}$ CAR $(1,872)$ lebih kecil dari $t_{\text {tabel }}(1,960)$, sehingga $\mathrm{H}_{\mathrm{o}}$ diterimadan $\mathrm{H}_{\mathrm{a}}$ ditolak. Kesimpulannya variabel CAR tidak berpengaruh terhadap variabel ROA. Berdasarkan signifikansi, nilai signifikansi CAR (probabilitas 0,063$)$ lebih besar dari taraf signifikansi $(0,05)$, sehingga $\mathrm{H}_{\mathrm{o}}$ diterima dan $\mathrm{H}_{\mathrm{a}}$ ditolak. Kesimpulannya variabel CAR tidak berpengaruh signifikan terhadap variabel ROA.

b. $\mathrm{t}$ hitung NPF (8,760 bertanda negatif) lebih kecil dari $\mathrm{t}$ tabel $(1,960)$, sehingga $\mathrm{H}_{\mathrm{o}}$ diterima dan $\mathrm{H}_{\mathrm{a}}$ ditolak. Kesimpulannya variabel NPF tidak berpengaruh terhadap variabel ROA. Berdasarkan signifikansi, nilai signifikansi NPF (probabilitas 0,000) lebih kecil dari taraf signifikansi 
$(0,05)$, sehingga $H_{o}$ ditolak dan $H_{a}$ diterima. Kesimpulannya variabel NPF berpengaruh signifikan terhadap variabel ROA.

c. $t_{\text {hitung }}$ FDR $(3,814)$ lebih besar dari $t_{\text {tabel }}(1,960)$, sehingga $H_{o}$ ditolak dan $\mathrm{H}_{\mathrm{a}}$ diterima. Kesimpulannya variabel FDR berpengaruh terhadap variabel ROA. Namun, nilai signifikansi FDR (probabilitas 0,000) lebih kecil dari taraf signifikansi $(0,05)$, sehingga $\mathrm{H}_{\mathrm{o}}$ ditolak dan $\mathrm{H}_{2}$ diterima. Kesimpulannya variabel FDR berpengaruh signifikan terhadap variabel ROA.

d. $\mathrm{t}$ hitung BOPO (9,336 bertanda negatif) lebih kecil dari $\mathrm{t}$ tabel $(1,960)$, sehingga $\mathrm{H}_{\mathrm{o}}$ diterima dan $\mathrm{H}_{\mathrm{a}}$ ditolak. Kesimpulannya variabel BOPO tidak berpengaruh terhadap variabel ROA. Berdasarkan signifikansi, nilai signifikansi FDR $(0,000)$ lebih kecil dari taraf signifikansi $(0,05)$, sehingga $\mathrm{H}_{\mathrm{o}}$ ditolak dan $\mathrm{H}_{\mathrm{a}}$ diterima. Kesimpulannya variabel $\mathrm{BOPO}$ berpengaruh signifikan terhadap variabel ROA.

2. Interpretasi dari persamaan regresi linier berganda:

$$
\mathrm{ROA}=3,221+0,009 \mathrm{X}_{1}-0,195 \mathrm{X}_{2}+0,019 \mathrm{X}_{3}-0,033 \mathrm{X}_{4}
$$

a. Konstanta sebesar 3,221 menyatakan bahwa jika tidak ada rasio CAR $\left(\mathrm{X}_{1}\right)$, rasio $\mathrm{NPF}\left(\mathrm{X}_{2}\right)$, rasio $\mathrm{FDR}\left(\mathrm{X}_{3}\right)$ dan rasio BOPO $\left(\mathrm{X}_{4}\right)$, maka rasio ROA adalah $3,221 \%$.

b. Koefisien regresi CAR sebesar 0,009 menyatakan bahwa setiap penambahan (karena bertanda +) rasio besarnya jumlah modal yang dimiliki oleh bank terhadap bobot risiko atas aktiva yang dimiliki oleh bank sebesar $1 \%$ akan meningkatkan rasio perbandingan laba bersih sebelum pajak terhadap total aktiva sebesar 0,009\% dengan catatan variabel lain dianggap tetap.

c. Koefisien regresi NPF sebesar 0,195 menyatakan bahwa setiap pengurangan (karena bertanda -) rasio pembiayaan bermasalah sebesar $1 \%$ akan akan mengurangi rasio perbandingan laba bersih sebelum pajak terhadap total aktiva sebesar $0,195 \%$ dengan catatan variabel lain dianggap tetap.

d. Koefisien regresi FDR sebesar 0,019 menyatakan bahwa setiap penambahan (karena bertanda + ) rasio pembiayaan terhadap DPK sebesar $1 \%$ akan meningkatkan rasio perbandingan laba bersih sebelum 
pajak terhadap total aktiva sebesar $0,019 \%$ dengan catatan variabel lain dianggap tetap.

e. Koefisien regresi BOPO sebesar 0,033 menyatakan bahwa setiap pengurangan (karena bertanda -) rasio kemampuan bank dalam melakukan kegiatan operasional sebesar 1\% akan mengurangi rasio perbandingan laba bersih sebelum pajak terhadap total aktiva sebesar $0,033 \%$ dengan catatan variabel lain dianggap tetap.

\section{Kesimpulan}

Temuan yang didapat berdasarkan hasil penelitian dan pembahasan yang sudah diuraikan dapat dilihat sebagai berikut:

1. Interpretasi dari persamaan regresi linier berganda bermakna besarnya koefisien regresi CAR sebesar 0,009 menunjukkan setiap penambahan $($ karena bertanda + ) rasio CAR bank syariah sebesar 1\% akan meningkatkan rasio perbandingan laba bersih sebelum pajak terhadap total aktiva sebesar 0,009\%, sehingga total aktiva yang dipergunakan mampu memberikan laba bersih bagi bank syariah. Besarnya koefisien regeresi CAR sesuai teori. Jika semakin besar penambahan rasio CAR, maka semakin baik posisi modal sebuah bank syariah yang berdampak pada meningkatnya ROA. Namun, tidak pada hasil uji t. Variabel CAR tidak berpengaruh dan tidak signifikan terhadap variabel ROA, sehingga total aktiva yang dipergunakan tidak mampu memberikan laba bersih.

2. Interpretasi dari persamaan regresi linier berganda dan hasil uji t sesuai teori. Besarnya koefisien regresi NPF sebesar 0,195 menunjukkan setiap pengurangan (karena bertanda -) rasio NPF bank syariah sebesar 1\% akan mengurangi rasio perbandingan laba bersih sebelum pajak terhadap total aktiva sebesar $0,195 \%$, sehingga risiko berupa kesulitan pengembalian pembiayaan oleh nasabah yang dapat mempengaruhi kinerja bank syariah dapat diminimalisir. Pada hasil uji t diketahui variabel NPF tidak berpengaruh dan signifikan terhadap variabel ROA. Jika semakin kecil pengurangan rasio NPF, maka kualitas pembiayaan bank syariah semakin baik. Bertambahnya NPF akan mengakibatkan hilangnya kesempatan untuk memperoleh laba bersih dari pembiayaan yang diberikan, sehingga berpengaruh buruk pada ROA. 
3. Interpretasi dari persamaan regresi linier berganda dan hasil uji t sesuai teori. Besarnya koefisien regresi FDR sebesar 0,019 menunjukkan setiap penambahan (karena bertanda + ) rasio FDR bank syariah terhadap pihak ketiga (DPK) sebesar 1\% akan meningkatkan rasio perbandingan laba bersih sebelum pajak terhadap total aktiva sebesar $0,019 \%$, sehingga peningkatan DPK tanpa diimbangi peningkatan pembiayaan akan mengurangi bagi hasil yang diterima nasabah. Pada hasil uji t diketahui variabel FDR berpengaruh dan signifikan terhadap variabel ROA. Jika semakin besar penambahan rasio FDR, maka pendapatan yang diperoleh bank syariah ikut naik. Berkurangnya FDR akan menyebabkan DPK nasabah yang dikelola bank syariah dapat ditarik sewaktu-waktu karena bersifat jangka pendek, sehingga bank syariah kesulitan memenuhi kebutuhan likuditas.

4. Interpretasi dari persamaan regresi linier berganda dan hasil uji t sesuai teori. Besarnya koefisien regresi BOPO sebesar 0,033 menunjukkan bahwa setiap pengurangan (karena bertanda -) rasio BOPO bank syariah dalam melakukan kegiatan operasional sebesar $1 \%$ akan mengurangi rasio perbandingan laba bersih sebelum pajak terhadap total aktiva sebesar 0,033\%, sehingga kemungkinan suatu bank syariah dalam kondisi bermasalah semakin kecil. Pada hasil uji t diketahui variabel BOPO tidak berpengaruh dan signifikan terhadap variabel ROA. Jika semakin kecil pengurangan rasio BOPO, maka semakin efisien biaya operasional yang dikeluarkan bank syariah. Bertambahnya BOPO menunjukkan keadaan yang kurang baik karena setiap rupiah penjualan yang terserap dalam biaya tinggi dan yang tersedia untuk laba bersih biayanya kecil.

Agar penelitian ini mendekati kesempurnaan, maka penulis menyarankan untuk peneliti lain melanjutkan penelitian dengan menambah masa periode penelitian (data), variabel penelitian dan objek penelitian, sehingga hasilnya lebih bervariasi dan representatif yang tentunya hasilnya signifikan berdasarkan teori (literature review). 


\section{Catatan}

${ }^{1}$ Di tahun 1992, lembaga keuangan syariah yang pertama berdiri di Indonesia berupa bank syariah adalah Bank Muamalat Indonesia (BMI). Munculnya Bank Muamalat Indonesia dilatarbelakangi karena adanya rekomendasi lokakarya ulama tentang bunga bank dan perbankan yang berlangsung di Cisarua, Bogor, pada tanggal 19-22 Agustus 1990. Hasil lokakarya tersebut dibahas lebih mendalam pada Musyawarah Nasional (Munas) IV Majelis Ulama Indonesia (MUI) yang berlangsung di Hotel Sahid Jaya, Jakarta, pada tanggal 22-25 Agustus 1990. Berdasarkan amanat Munas IV MUI dibentuklah kelompok kerja untuk mendirikan bank syariah di Indonesia. Padahal keinginan umat Islam Indonesia akan adanya bank yang beroperasi sesuai dengan prinsipprinsip syariah Islam sudah sejak lama digagas oleh para tokoh dan cendikiawan muslim Indonesia sejak tahun 1930an. Disebutkan di tahun 1937, Kyai Haji Mansur, Ketua Pengurus Pusat (PP) Muhammadiyah Periode 1937-1944 telah mengemukakan pendapatnya tentang keharaman menggunakan jasa perbankan konvensional bagi umat Islam dan memunculkan gagasan untuk mendirikan bank Islam di Indonesia.

${ }^{2}$ Penyebutan Bank Islam di Indonesia adalah Bank Syariah.

${ }^{3}$ Landasan hukum perbankan syariah adalah Undang-Undang Nomor 7 Tahun 1992 Tentang Perbankan memberikan peluang untuk membuka bank yang beroperasi dengan prinsip bagi hasil. Indonesia memasuki era dual banking systemdi mana bank dengan prinsip bagi hasil dan bank konvensional secara bersama-sama mendukung pembangunan perekonomian nasional tanggal 25 Maret 1992.Undang-Undang Nomor 10 Tahun 1998 yang merupakan amandemen dari Undang-Undang Nomor Nomor 7 Tahun 1992 tentang Perbankan, memberikan landasan hukum yang lebih kuat bagi keberadaan bank yang melakukan kegiatan usaha berdasarkan prinsip syariah. Bank konvensional dimungkinkan untuk membuka unit usaha syariah tanggal 10 November 1998. Lalu, Undang-Undang Nomor 23 Tahun 1999 yang selanjutnya diamandemen dengan UndangUndang Nomor 3 Tahun 2004 tentang Bank Indonesia tanggal 15 Januari 20014 memberi kewenangan kepada Bank Indonesia sebagai otoritas pengawasan perbankan syariah dan memungkinkan Bank Indonesia untuk dapat menggunakan instrumen kebijakan moneter berdasarkan prinsip syariah tanggal 17 Mei 1999.

${ }^{4}$ Lihat kembali Q.S. Al-Baqarah[2]: 275.

${ }^{5}$ Lihat kembali penilaian kesehatan bank syariah berdasarkan Peraturan Bank Indonesia (PBI) Nomor 9/1/PBI/2007 Tentang Sistem Penilaian Tingkat Kesehatan Bank Umum Berdasarkan Prinsip Syariah yang berlaku mulai 24 Januari 2007

${ }^{6}$ Kasmir, Dasar-Dasar Perbankan (Jakarta: PT. Rajagrafindo Persada, cet. ke-12, Agustus 2014), h. 254-255.

${ }^{7}$ Lukman Dendawijaya, Manajemen Perbankan (Jakarta:Ghalia Indonesia, 2009), h. 118.

${ }^{8}$ Imam Wahyudi dkk., Manajemen Risiko Bank Islam (Jakarta: Salemba Empat, 2013), h. 31.

9 Sutan Remy Sjahdeini, Perbankan Syariah: Produk-Produk dan Aspek-Aspek Hukumnya (Jakarta: Kencana Prenadamedia Group, 2014), h. 99-100.

${ }^{10}$ Irham Fahmi, PengantarManajemen Keuangan (Bandung:Alfabeta, 2016), h. 49-52.

${ }^{11}$ Ikatan Bankir Indonesia (IBI), Supervisi Manajemen Risiko Bank (Jakarta: PT. Gramedia Pustaka, 2016), h. 191.

12 Veithzal Rivai danArifinArviyan, Islamic Banking Sebuah Teori, Konsep dan Aplikasi(Jakarta: PT. Bumi Aksara, 2010),h. 850.

${ }^{13}$ Dwi Suwiknyo, Analisis Laporan Keuangan Perbankan Syariah(Yogyakara: Pustaka Pelajar, cetakan ke-2, 2016), h. 149.

${ }^{14}$ Muhammad Syafi'i Antonio, Bank Syariah: Dari Teori ke Praktik (Jakarta:Gema Insani, cetakan ke-1, 2001), h. 107.

${ }^{15}$ Mudrajad Kuncoro, Manajemen Perbankan: Teori dan Aplikasi (Yogyakarta: BPFE, 2002), h. 462 . 
${ }^{16}$ Veithzal Rivai, Credit Management Handbook: Manajemen Perkreditan Cara-Cara Mudah Menganalisis Kredit (Jakarta: PT. Rajagrafindo Persada,2013), h. 131. 101.

${ }^{17}$ Melayu Hasibuan, Manajemen Sumber Daya Manusia (Jakarta: Bumi Aksara, 2011),

${ }^{18}$ Muhammad, Bank Syariah Problem dan Prospek Perkembangan di Indonesia, Graha Ilmu, Yogyakarta, 2005, h. 265.

${ }^{19}$ Irham Fahmi, Pengantar Pasar Modal (Bandung: Alfabeta, 2012), h. 98.

${ }^{20}$ Kasmir, Manajemen Perbankan (Jakarta: PT. Rajagrafindo Persada, cetakan ke-12, Januari 2014), h. 327.

21 Hery, Analisis Laporan Keuangan: Pendekatan Rasio Keuangan(Jakarta: CAPS Publishing, Maret 2015), h. 226.

${ }^{22}$ Etta Mamang Sangadji dan Sopiah, Metodologi Penelitian: Pendekatan Praktis Dalam Penelitian (Yogyakarta: ANDI, 2010), h. 4.

${ }^{23}$ Kriteria keputusan dalam uji normalitas adalah jika nilai signifikansi lebih besar dari 0,05, maka data berdistribusi normal begitu sebaliknya. Dalam uji normalitas, metode pengujian yang penulis gunakan dengan melihat histogram display normal curve dan grafik normal probability plot.

${ }^{24}$ Pengujian selanjutnya dengan uji Kolmogorov Smirnov (K-S). Konsep dasar uji normalitas K-S membandingkan distribusi data (yang akan diuji normalitasnya) dengan distribusi normal baku. Nilai K-S $\mathrm{S}_{\text {hitung }}$ ditunjukkan dengan nilai Absolute pada Most Extreme Differences. Jika K-S $\mathrm{S}_{\text {hitung }}$ lebih kecil dari $\mathrm{K}-\mathrm{S}_{\text {tabel }}$, maka keputusannya data berdistribusi normal dan berlaku sebaliknya. Penerapan uji K-S juga dapat dilihat dari "Asymp. Sig (2-tailed)" baris paling bawah. Jika signifikansi nilai tiap variabel di atas 0,05 , maka uji normalitas bisa terpenuhi.

${ }^{25}$ Dalam uji heteroskedastisitas, metode pengujian melihat pola grafik scatter plot antara Standardized Predicted Value (ZPRED) dengan Studentized Residual (SRESID) dan pengujian uji Glejser.

${ }^{26}$ Uji autokorelasi akan diuji lagi dengan uji Runs dikarenakan pada uji sebelumnya (uji DW), terdapat autokorelasi. Pada prinsipnya, uji Runs ingin mengetahui apakah suatu rangkaian kejadian hal atau simbol merupakan hasil proses yang acak (random) dalam artian tidak direncanakan terlebih dahulu atau tidak membuat sebuah pola tertentu.

\section{Daftar Pustaka}

Antonio, Muhammad Syafi'i. Bank Syariah: Dari Teori ke Praktik. Jakarta: Gema Insani. 2001.

Dendawijaya, Lukman. Manajemen Perbankan. Jakarta:Ghalia Indonesia. 2009.

Fahmi, Irham. Pengantar Manajemen Keuangan. Bandung:Alfabeta. 2016.

Pengantar Pasar Modal. Bandung: Alfabeta. 2012.

Hasibuan, Melayu Hasibuan. Manajemen Sumber Daya Manusia. Jakarta: Bumi Aksara. 2011.

Hery. Analisis Laporan Keuangan: Pendekatan Rasio Keuangan. Jakarta: CAPS Publishing. 2015. 
Ikatan Bankir Indonesia (IBI). Supervisi Manajemen Risiko Bank. Jakarta: PT. Gramedia Pustaka. 2016.

Kasmir. Dasar-Dasar Perbankan Jakarta: PT. Rajagrafindo Persada. 2014. Manajemen Perbankan. Jakarta: PT. Rajagrafindo Persada. 2014.

Kuncoro, Mudrajad. Manajemen Perbankan: Teori dan Aplikasi. Yogyakarta: BPFE. 2002.

Muhammad. Bank Syariah Problem dan Prospek Perkembangan di Indonesia. Yogyakarta: Graha Ilmu. 2005.

Peraturan Bank Indonesia (PBI) Nomor 9/1/PBI/2007

Rivai, Veithzal, dan Arifin Arviyan. Islamic Banking Sebuah Teori, Konsep dan Aplikasi. Jakarta: PT. Bumi Aksara. 2010.

Rivai, Veithzal. Credit Management Handbook: Manajemen Perkreditan CaraCara Mudah Menganalisis Kredit. Jakarta: PT. Rajagrafindo Persada. 2013.

Sangandji, Etta Mamang dan Sopiah. Metodologi Penelitian: Pendekatan Praktis Dalam Penelitian. Yogyakarta: ANDI. 2010.

Sjahdeini, Sutan Remy. Perbankan Syariah: Produk-Produk dan Aspek-Aspek Hukumnya. Jakarta: Kencana Prenadamedia Group. 2014.

Suwiknyo, Dwi. Analisis Laporan Keuangan Perbankan Syariah. Yogyakara: Pustaka Pelajar. 2016.

Undang-Undang Nomor 10 Tahun 1998.

Undang-Undang Nomor 23 Tahun 1999

Undang-Undang Nomor 3 Tahun 2004.

Undang-Undang Nomor 7 Tahun 1992.

Wahyudi, Imam., et.al. Manajemen Risiko Bank Islam. Jakarta: Salemba Empat. 2013. 